\title{
Characterization of mucosa-associated Escherichia coli strains isolated from Crohn's disease patients in Brazil
}

\author{
Rafaella F. A. Costa ${ }^{1,2}$, Maria L. A. Ferrari ${ }^{3,4}$, Marie-Agnès Bringer ${ }^{5}$, Arlette Darfeuille-Michaud ${ }^{2}$, \\ Flaviano S. Martins ${ }^{1}$ and Nicolas Barnich ${ }^{2 *}$
}

\begin{abstract}
Background: Crohn's disease (CD) is characterized by chronic inflammation of the human intestine. Several studies have demonstrated that the intestinal mucosa of CD patients in Western countries is abnormally colonized by adherent-invasive Escherichia coli (AIEC) strains. However, no studies to date have focused on the involvement of such E. coli strains in CD patients in Brazil. Here, we characterized E. coli strains associated with the ileal mucosa of Brazilian CD patients (ileal biopsies from 35 subjects, 24 CD patients and 11 controls).

Results: The colonization level of adherent Enterobacteriaceae associated with the ileal mucosa of CD patients was significantly higher than that of the controls. The proportions of E. coli strains belonging to phylogroups B1 and B2 were two-fold higher in strains isolated from CD patients than in those isolated from controls. CD patients in the active phase harbored 10-fold more E. coli belonging to group B2 than CD patients in remission. Only a few E. coli isolates had invasive properties and the ability to survive within macrophages, but 25\% of CD patients in Brazil (6/ 24) harbored at least one E. coli strain belonging to the AIEC pathobiont. However, fimH sequence analysis showed only a few polymorphisms in the FimH adhesin of strains isolated in this study compared to the FimH adhesin of AIEC collections isolated from European patients.

Conclusions: Mucosa-associated E. coli strains colonize the intestinal mucosa of Brazilian CD patients. However, the strains isolated from Brazilian CD patients have probably not yet co-evolved with their hosts and therefore have not fully developed a strong adherent-invasive phenotype. Thus, it will be crucial to follow in the future the emergence and evolution of AIEC pathobionts in the Brazilian population.
\end{abstract}

Keywords: Crohn's disease, Inflammatory bowel disease, Mucosa-associated Escherichia coli

\section{Background}

Crohn's disease $(\mathrm{CD})$ is an inflammatory bowel disease (IBD) characterized by chronic inflammation of the human intestine [1]. The etiology of $C D$ remains unknown, but the most common hypothesis is that chronic inflammation results from an abnormal inflammatory response

\footnotetext{
* Correspondence: nicolas.barnich@uca.fr

Arlette Darfeuille-Michaud is deceased.

2Université Clermont Auvergne, Inserm U1071, M2iSH, USC-INRAE 2018, 28

place Henri Dunant, 63000 Clermont-Ferrand, France

Full list of author information is available at the end of the article
}

to intestinal microbiota in a genetically susceptible host [2]. Recent studies have suggested that the composition of intestinal microbiota contributes to $\mathrm{CD}$ pathogenesis. In humans, the first evidence of the involvement of intestinal microbiota in IBD came from clinical data showing that diverting the flow of feces relieved the symptoms of CD [3]. Different theories regarding the role of the intestinal microbiota in CD have been developed, in particular the theory of dysbiosis and that of a persistent pathogenic infectious agent in the intestinal

C C The Author(s). 2020 Open Access This article is licensed under a Creative Commons Attribution 4.0 International License, which permits use, sharing, adaptation, distribution and reproduction in any medium or format, as long as you give appropriate credit to the original author(s) and the source, provide a link to the Creative Commons licence, and indicate if changes were made. The images or other third party material in this article are included in the article's Creative Commons licence, unless indicated otherwise in a credit line to the material. If material is not included in the article's Creative Commons licence and your intended use is not permitted by statutory regulation or exceeds the permitted use, you will need to obtain permission directly from the copyright holder. To view a copy of this licence, visit http://creativecommons.org/licenses/by/4.0/ The Creative Commons Public Domain Dedication waiver (http://creativecommons.org/publicdomain/zero/1.0/) applies to the data made available in this article, unless otherwise stated in a credit line to the data. 
mucosa. However, no specific pathogen has yet been definitively identified.

E. coli is an important microorganism of the human intestinal microbiota and plays an important role in promoting the stability and maintenance of intestinal physiology. Through the acquisition of virulence factors, some strains of $E$. coli have become pathogenic and are implicated in the etiology of IBD [4]. The search for specific pathogens in the intestinal mucosa of patients with CD has resulted in the identification in 1998 of several candidates, among which Adherent-Invasive E. coli (AIEC) have much supporting evidence [5]. Since, a higher prevalence of such AIEC pathobionts, with proinflammatory potential, in $\mathrm{CD}$ patients compared to healthy subjects, have been reported in various western countries [6-8]. AIEC bacteria behave like pathobiont bacteria rather than real pathogens, and must share in the evolution of common ancestors with ExPEC strains [9]. These bacteria could be the results of an adaptation of non-pathogenic bacteria to environmental factors leading to a phenotypic characteristic. Moreover, this group of bacteria is very heterogeneous (as example AIEC isolated from adults [6, 9-11], children [12, 13], and companion animals [14]) from a phylogenic point of view, which makes it difficult to characterize them at the molecular level. The phenotypic characteristics of these bacteria are: (1) adhesion and invasion of intestinal epithelial cells, involving a process of actin polymerization and recruitment of microtubules [5, 14], and (2) survival and replication in macrophages, leading to the massive release of the cytokine TNF, without inducing the death of the infected macrophage [15]. Two AIEC strains able to adhere to and invade different intestinal epithelial cell lines were isolated from a chronic ileal lesion in a patient with $C D$ (AIEC LF82 (O83:H1) and NRG857c); these strains have been fully identified and closely studied [5, 14]. AIEC are distinct from other pathogenic intestinal $E$. coli in that they do not harbor genes typically associated with other pathogens $[14,16]$. Several AIEC genomes were recently sequenced, and comparative genomic studies of $E$. coli strains isolated from patients with $C D$ showed that these strains represent a heterogeneous population with a genomic profile similar to that of extraintestinal pathogenic E. coli strains (ExPEC) [17-21]. AIEC colonization in mice leads to strong inflammatory responses in the gut, suggesting that AIEC could play a role in CD immunopathogenesis $[10,11]$. Furthermore, the presence of AIEC in the mucosa of CD patients at initial diagnosis suggests that these microorganisms may play a role in the early stages of disease onset [12].

Much of the work on this organism, and its potential role in $\mathrm{CD}$, has been undertaken in Europe, North America and Australia. However, to truly consider the involvement of AIEC in CD, the presence of these bacteria in patients in other parts of the world, including countries with high disease incidence and countries with increasing disease incidence, need to be demonstrated. In the past few decades, the incidence of $C D$ has been increasing in developing countries. No studies have focused on the involvement of such $E$. coli strains in CD patients in Brazil. A recent study detected invasive $E$. coli in the ileum and stools of a CD patient. This strain, while able to adhere to and invade epithelial cells, does not have all the AIEC criteria [22]. The aim of this study was to isolate and characterize E. coli strains, particularly AIEC, associated with ileal mucosa in Brazilian CD patients.

\section{Results}

\section{Patient characteristics}

The median ages of in CD patients and healthy controls were $42.3 \pm 12.0$ years and $57.1 \pm 13.4$ years, respectively. There were 16 female and 8 male CD patients and 6 women and 5 men in the control group. The ileocolonic area was the most predominantly affected (14 patients: $58.3 \%$ ), followed by the ileum (9 patients: $37.5 \%)$. Colon involvement was present in only one patient (4.1\%). Stenosis was observed in $33.3 \%$ of patients, penetrating disease in $25.0 \%$, and neither stenosis nor penetrating disease in $20.8 \%$. Patient characteristics are shown in Table 1, patient distribution according to age at $C D$ diagnosis is shown in Table 1, patient distribution according to disease localization is shown in Table 2, and patient distribution according to disease behavior is shown in Table 2.

\section{Mucosa-associated Enterobacteriaceae in CD patients and controls}

Mucosa-associated E. coli were isolated from all controls and $\mathrm{CD}$ patients. However, a significant 6.45 -fold increase $(p=0.0252)$ in the level of mucosa-associated $E n$ terobacteriaceae was observed in the ileal mucosa of $\mathrm{CD}$ patients (median: $3.1 \times 10^{5} \mathrm{CFU} / \mathrm{g}$ of tissue) compared with that of controls (median: $4.8 \times 10^{4} \mathrm{CFU} / \mathrm{g}$ of tissue) (Fig. 1), indicating a higher colonization rate of intestinal mucosa in CD patients than in controls.

Of the 270 Enterobacteriaceae isolates obtained in this study, 241 were identified as E. coli strains (58 in controls and 183 in $\mathrm{CD}$ patients). Concerning the other 29 isolated strains, 10 were Klebsiella sp. (2 in control

Table 1 Patient characteristics

\begin{tabular}{|c|c|c|c|c|}
\hline \multirow[t]{2}{*}{ Patients } & \multirow[t]{2}{*}{$\mathrm{N}$} & \multirow{2}{*}{$\begin{array}{l}\text { Gender } \\
\text { F/M }\end{array}$} & \multicolumn{2}{|l|}{ Age (Years) } \\
\hline & & & Average $\pm S D$ & Age range \\
\hline Control & 11 & $6 / 5$ & $57.1 \pm 13.4$ & $28-81$ \\
\hline CD & 24 & $16 / 8$ & $42.3 \pm 12.0$ & $18-66$ \\
\hline Total & 35 & $22 / 13$ & $46.1 \pm 12.9$ & $18-81$ \\
\hline
\end{tabular}

$N$ number, $F$ female, $M$ male, $S D$ standard deviation 
Table 2 Montreal classification of Crohn's disease

\begin{tabular}{ll}
\hline Criteria & $\mathrm{n}(\%)$ \\
\hline Age at Diagnosis (A) & $2(8.3 \%)$ \\
A1: 16 years or less & $17(70.8 \%)$ \\
A2: 17-40 years & $5(20.8 \%)$ \\
A3: 40 years or more & \\
Localization (L) & $9(37.5 \%)$ \\
L1: Terminal lleum & $1(4.2 \%)$ \\
L2: Colon & $14(58.3 \%)$ \\
L3: lleocolonic & \\
Behavior (B) & $5(20.8 \%)$ \\
B1: Not stenting, non-penetrating & $8(33.3 \%)$ \\
B2: Stenting & $6(25.0 \%)$ \\
B3: Penetrating & $1(4.2 \%)$ \\
B1p: Not stenting, non-penetrating + perianal fistula & $2(8.3 \%)$ \\
B2p: stenting + perianal fistula & $2(8.3 \%)$ \\
B3p: penetrating + perianal fistula
\end{tabular}

subjects and 8 in CD patients) and 19 were Enterobacter sp. (2 in control subjects and 17 in CD patients). All identification was made by nonautomated tests.

\section{Phylogeny of $E$. coli strains associated with intestinal} mucosa

Analysis of the phylogroup distribution of $E$. coli isolated from controls and $\mathrm{CD}$ patients showed no significant difference between the two groups $(p=0.3797)$ (Table 3$)$. In the controls, most $E$. coli strains belonged to phylogroups A (44.8\%) and D (36.2\%). In CD patients, most strains belonged to phylogroups A (37.2\%) and B1 (27.9\%). The proportions of E. coli strains belonging to phylogroups B1 and B2 were two-fold higher in strains isolated from $\mathrm{CD}$ patients (B1, 27.9\%; B2, 11.5\%) than in those isolated from controls (B1, 13.8\%; B2, 5.2\%). Interestingly, $C D$ patients in the active phase (20.2\%) harbored 10-fold more E. coli strains belonging to the B2 group than $\mathrm{CD}$ patients in remission $(2.0 \%)$ and 2.4-fold fewer strains of group D $(12.8 \% \mathrm{CD}$ active vs $31.3 \% \mathrm{CD}$ remission).

\section{Ability of $E$. coli strains to invade human intestinal epithelial cells}

We determined the ability of the $241 \mathrm{E}$. coli strains isolated in this study to invade human intestinal epithelial I-407 cells. Intracellular bacteria with an abundance equal to or greater than $0.1 \%$ compared to the inoculum were classified as invasive to I-407 cells [23]. Of the 241 E. coli strains isolated from intestinal mucosa, 13 (5.4\%) were considered invasive to epithelial cells, 7 strains in the control group and 6 in $\mathrm{CD}$ patients (Fig. 2). There was no global significant difference between the cell invasion profile of strains isolated from the mucosa of the control and CD groups $(p=0.9225)$. Assessment of controls and $C D$ patients showed that the abundances of most intestinal-associated E. coli strains (94.6\%) were

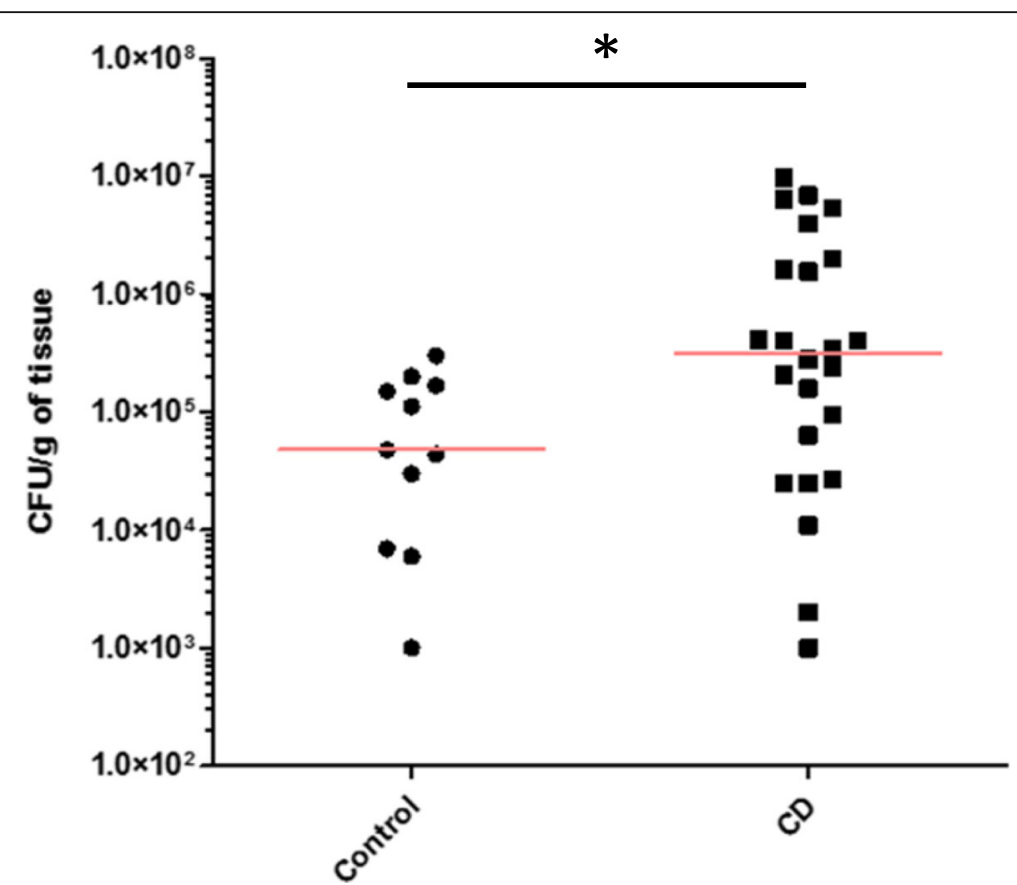

Fig. 1 Quantification of Enterobacteriaceae associated with the ileal mucosa of controls and patients with CD. The value of the median is shown in red. The statistical analysis was performed using the nonparametric Mann-Whitney test. * $p<0.05$ 
Table 3 Distribution of E. coli strains among the phylogenetic groups

\begin{tabular}{lrllll}
\hline Patients & Strains & \multicolumn{4}{l}{ Phylogenetic groups } \\
\cline { 3 - 6 } & & A & B1 & B2 & D \\
\hline Control & 58 & $26(44.83 \%)$ & $8(13.79 \%)$ & $3(5.17 \%)$ & $21(36.21 \%)$ \\
CD & 183 & $68(37.16 \%)$ & $51(27.87 \%)$ & $21(11.48 \%)$ & $43(23.50 \%)$
\end{tabular}

${ }^{\mathrm{a}}$ The statistical analysis was performed by the Kruskal-Wallis test adjusted by Dunn's test. No statistical difference was observed

lower than $0.1 \%$, indicating that most strains isolated in this study had not yet evolved to select the ability to invade intestinal epithelial cells.

\section{Survival and replication within THP-1 cells}

All 13 E. coli strains considered invasive to I-407 cells were used for intracellular replication assays in human THP-1 macrophages. Assay results with values significantly higher than $100 \%$ (percentage of the number of bacteria at $6 \mathrm{~h}$ post-infection compared to $1 \mathrm{~h}$ postinfection) indicated that the strains were able to replicate within THP-1 cells after $24 \mathrm{~h}$ of infection. Of the strains tested in this study, 9 E. coli strains (3 in the control group and 6 in CD patients) were able to multiply within macrophages (Fig. 3). As these 9 E. coli strains were invasive to I-407 cells and were able to replicate within THP-1 cells, they were classified as AIEC. The ability of two out of 9
AIEC strains isolated from CD patients (samples CD5 and CD6) to survive in THP-1 cells was significantly high compared to the reference AIEC strain LF82. The production of TNF- $\alpha$ in THP-1 cells infected with the $9 E$. coli strains identified as AIEC was measured. The strain LF82 was used as a positive control, and $E$. coli $\mathrm{K}-12$, which is unable to replicate in macrophages, was used as a negative control. TNF- $\alpha$ levels were significantly higher in cells infected with AIEC strains than in uninfected cells (Fig. 4). There was no significant difference in TNF- $\alpha$ levels between AIEC strains isolated from controls and CD patients. In conclusion, 6 out of $24 \mathrm{CD}$ patients harbor at least one AIEC strain (25\%) compared to 3 out of 11 controls (27\%).

\section{Association between AIEC profile and the presence of putative virulence factors and/or fimH polymorphisms} We first looked for the presence of the $h c p 1$ and hcp3 genes, one of the genes of the type VI secretion system potentially involved in AIEC virulence, and the $l f p \mathrm{~A}$ and gipA genes, involved in the ability of AIEC to interact with Peyer's patches, in AIEC strains isolated from Brazilian CD patients. We observed no association between the presence of these four genes and the AIEC phenotype of AIEC strains isolated from Brazilian CD patients (Table 4).

ns

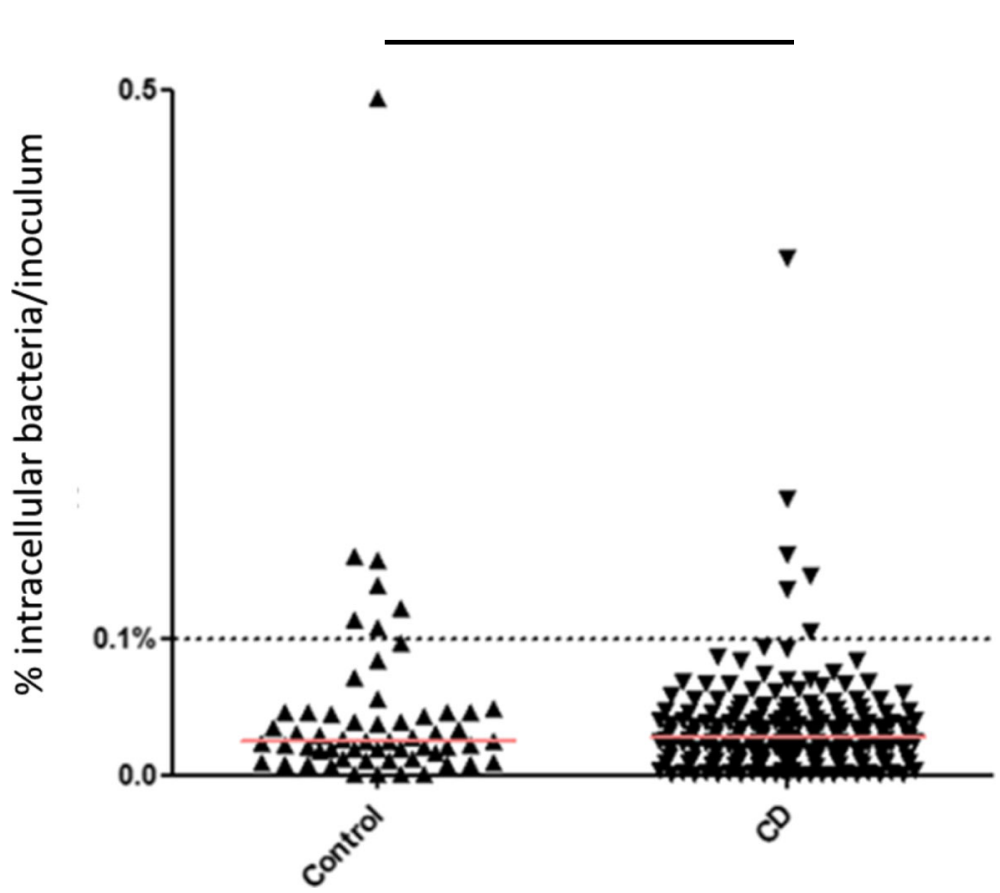

Fig. 2 Invasive ability of E. coli strains. The results are expressed as the percentage of inoculum surviving in human Intestine-407 epithelial intestinal cells after $3 \mathrm{~h}$ of infection and $1 \mathrm{~h}$ of gentamicin treatment. The value of the median is shown in red. The statistical analysis was performed using the nonparametric Mann-Whitney test. n.s. $p>0.05$ 


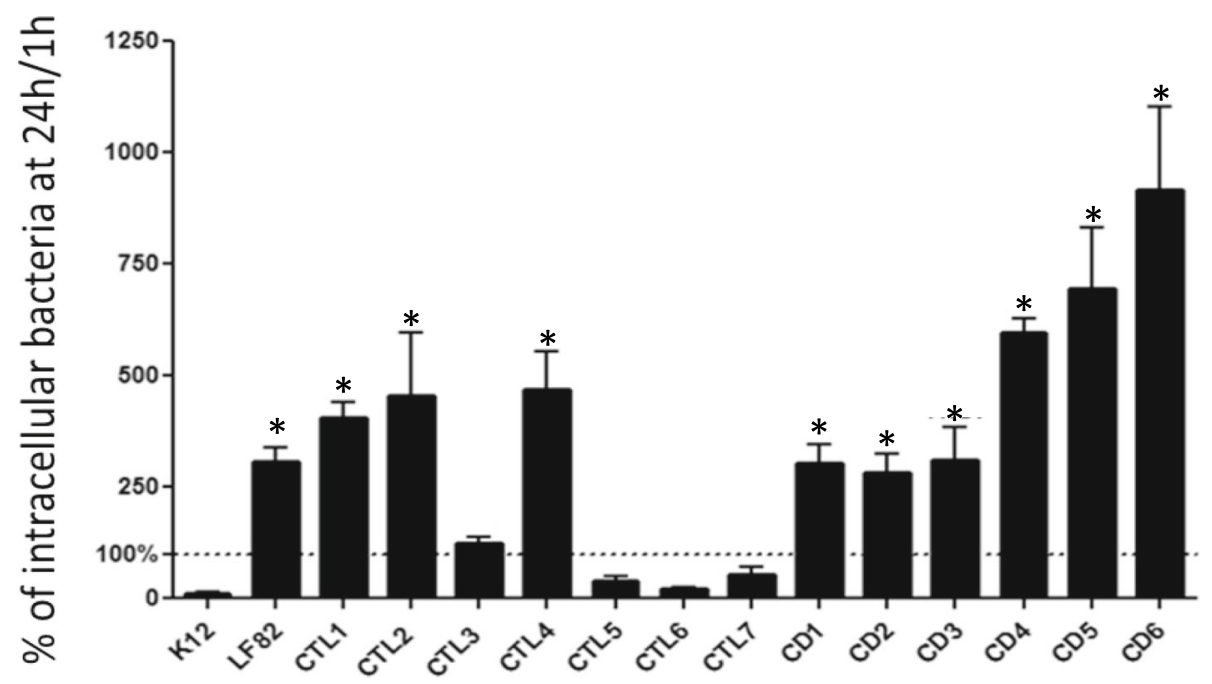

Fig. 3 Survival and replication of E. coli strains within THP-1 cells. CTL, control subject samples; CD, CD patient samples. The statistical analysis was performed using a nonparametric Mann-Whitney test to determine if the value corresponding to the number of intracellular bacteria at $6 \mathrm{~h}$ postinfection was significantly higher than the value at $1 \mathrm{~h}$ post infection for each strain. ${ }^{*} p<0.05$

In addition, the fim $\mathrm{H}$ gene in all AIEC strains isolated in this study was sequenced. For comparison, the fim $\mathrm{H}$ sequences of the LF82 and K12 strains were used for the alignment of the fim $\mathrm{H}$ sequences. In the 9 AIEC strains, 43 single base polymorphisms (SNPs) were identified in the fim $\mathrm{H}$ gene, resulting in the substitution of eight amino acids in the protein sequence. Of the 9 AIEC strains, 8 had at least one amino acid polymorphism, and only 1 (isolated from the control group, CTL2) had $100 \%$ similarity compared to the fim $\mathrm{H}$ gene of E. coli K12 (Table 5). Only the V27A mutation was observed in the strains isolated in this study. As reported elsewhere [24], the V27A polymorphism is not found exclusively in
AIEC strains. Thus, this variation is not classified as an exclusive pathoadaptive change associated with the AIEC phenotype but could be a mark of the transition from commensalism to pathobionts in E. coli.

\section{Discussion}

The intestinal microbiota has been associated with the etiopathogenesis of IBD [25]. Changes in the composition of the enteric microbial community, with a decrease in the number of resident bacterial species and an increase in the number of bacteria associated with the mucosa, have been observed in CD. Several independent studies have shown a considerable increase in the

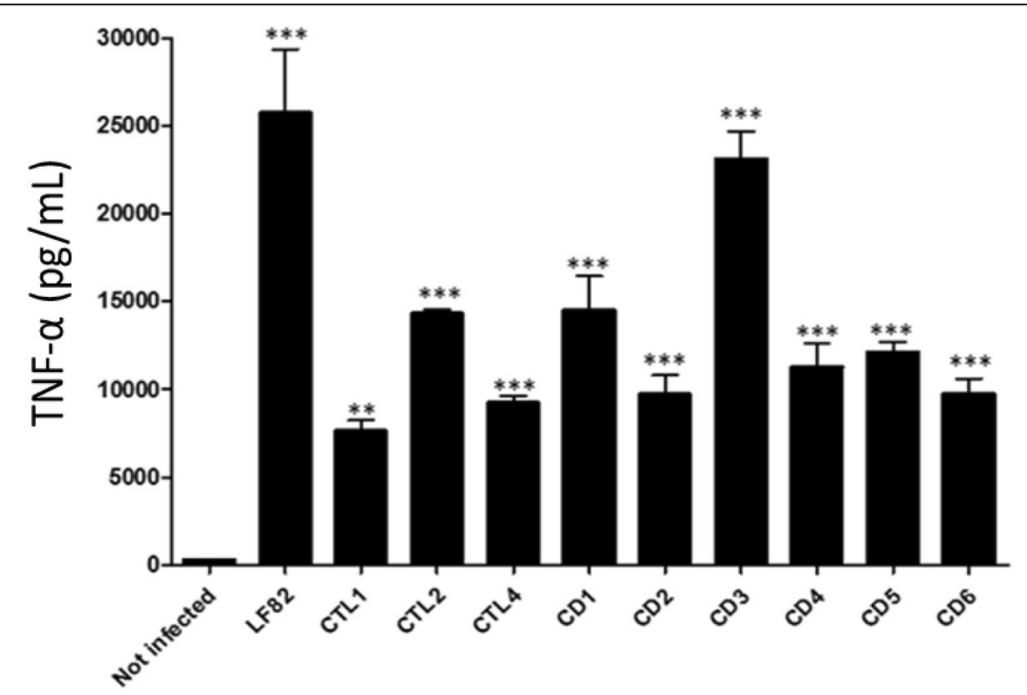

Fig. 4 TNF-a levels produced by THP-1 cells infected with AIEC strains. CTL, control subject samples; CD, CD patient samples. Statistical analysis was performed by one-way ANOVA followed by the Newman-Keuls test. ${ }^{* *} p<0.01$, ${ }^{* *} p<0.001$ (compared to noninfected cells) 
Table 4 Analysis of the presence of putative virulence factors in AIEC strains

\begin{tabular}{llllll}
\hline Strains & Phylogroup & hcp 1 & hcp 3 & Ipf A & gip $\mathrm{A}$ \\
\hline LF82 & B2 & + & + & + & + \\
CTL1 & B2 & - & + & - & - \\
CTL2 & D & + & - & - & - \\
CTL4 & A & - & - & - & - \\
CD1 & B1 & - & - & + & - \\
CD2 & B1 & - & - & + & - \\
CD3 & B2 & - & - & - & - \\
CD4 & B1 & - & - & - & - \\
CD5 & B1 & - & - & - & - \\
CD6 & B1 & - & - & - & - \\
\hline
\end{tabular}

population of Enterobacteriaceae, especially E. coli, in the intestinal mucosa of $\mathrm{CD}$ patients compared to control subjects [26, 27]. Several studies have demonstrated that the intestinal mucosa of CD patients in Western countries is abnormally colonized by pathobiont Escherichia coli strains with adherent and invasive properties (AIEC) [5-13, 23, 28]. Much of the work on AIEC, as well as their potential role in $\mathrm{CD}$, has been undertaken in areas of high CD incidence (Europe, North America and Australia). It was currently unclear whether the changes in such putative pathogen organisms identified in Western populations are more widespread in IBD patients in regions with increasing IBD incidence, especially in Latin America and more specifically in Brazil.

Phylogenetic analyses have shown that E. coli strains are classified into four main phylogenetic groups (A, B1, B2 and D). Here, we demonstrate that the mucosa of

Table 5 Substitutions of amino acid residues in the AIEC strains

\begin{tabular}{|c|c|c|c|c|c|c|c|c|c|c|}
\hline \multirow[t]{3}{*}{ Strains } & \multicolumn{10}{|c|}{ Mutations at amino acid residue } \\
\hline & \multicolumn{10}{|c|}{ Leader Lectin domain Pilin domain peptide } \\
\hline & 6 & 26 & 27 & 66 & 70 & 78 & 119 & 158 & 202 & 269 \\
\hline K12 & $\mathbf{T}$ & $\mathbf{P}$ & $\mathbf{v}$ & G & $\mathbf{N}$ & $\mathrm{S}$ & A & $T$ & A & $\mathbf{Q}$ \\
\hline LF82 & & & A & & $S$ & N & & P & & \\
\hline CTL1 & & & A & & & & & & & K \\
\hline \multicolumn{11}{|l|}{ CTL2 } \\
\hline CTL4 & & & A & S & & & & & V & \\
\hline DC1 & & $\mathrm{L}$ & A & & & & & & & \\
\hline DC2 & & $\mathrm{L}$ & A & & & & & & & \\
\hline DC3 & & & A & & $\mathrm{H}$ & & & & & \\
\hline DC4 & & & A & & & & & & & \\
\hline DC5 & & & A & & & & & & & \\
\hline DC6 & & & A & & & & & & & \\
\hline
\end{tabular}

Brazilian CD patients is also heavily colonized by Enterobacteriaceae, mostly by E. coli strains. The strains isolated in this study have a more homogeneous profile when classified according to the major phylogenetic groups. However, we observed a considerable increase in the phylogroups $\mathrm{B} 1$ and $\mathrm{B} 2$ in Brazilian $\mathrm{CD}$ patients compared to controls, and the $\mathrm{CD}$ patients in the active phase harbored 10-fold more E. coli belonging to the B2 group than $C D$ patients in remission. The $E$. coli strains belonging to groups $\mathrm{A}$ and $\mathrm{B} 1$ are weakly or nonpathogenic, while those belonging to groups $\mathrm{B} 2$ and $\mathrm{D}$ are most often pathogenic and are commonly associated with urinary tract and extraintestinal infections [29-32]. E. coli strains isolated from IBD patients in Western countries are mostly classified into groups B2 and D. While some researchers observed a similar distribution of phylogenetic groups in the control and IBD groups [13, 33-38], other studies, in agreement with our data, have reported increased colonization by strains belonging to groups $\mathrm{B} 2$ and $\mathrm{D}$ in IBD patients compared to controls [10, 24].

Several factors of CD predispose patients to the emergence of an intestinal microenvironment advantageous for effective colonization by $E$. coli, thereby contributing to susceptibility to the disease. As stated previously, E. coli is an important microorganism of the normal intestinal microbiota. However, E. coli strains associated with the mucosa of $\mathrm{CD}$ patients possess unusual properties, such as the ability to adhere to and invade the intestinal epithelium and to multiply within macrophages, leading to the production of large amounts of TNF- $\alpha[5,14,15,23]$. The results of our study show that most $E$. coli strains isolated in both CD patients and controls did not have the invasive phenotype. However, 6 out of $24 \mathrm{CD}$ patients harbored at least one strain with characteristics of AIEC. This prevalence of CD patients harboring AIEC bacteria is consistent with data reported in the literature of adult cohorts [39]. In contrast, the prevalence of AIEC bacteria in the controls in this study was abnormally high compared to the literature. This can be explained by the low number of controls included $(n=11)$ and by the fact that the controls were hospitalized patients without IBD but with other comorbidities. The 3 control patients harboring AIEC bacteria had schistosomiasis (CTL1), gallbladder neoplasia in 2009 and cholecystectomy in 2009 (CTL2), and Still's disease-rheumatic fever (CTL3). However, several independent studies have demonstrated that the mucosa of $\mathrm{CD}$ patients is heavily colonized by AIEC strains in comparison to a control group. The reasons for this discrepancy are not fully understood. However, it is believed that the presence of AIEC associated with the mucosa of CD patients can vary according to different populations. One of the hypotheses to explain the high prevalence of AIEC in Western countries is environmental exposure over a 
long period. It is likely that over the next few decades, $E$. coli with invasive properties will be selected in the ileal mucosa of Brazilian CD patients with abnormal colonization of adherent E. coli as Brazilian CD patients gradually adopt a more Western lifestyle; alternatively, the ileal mucosa of Brazilian CD patients could be contaminated by more aggressive AIEC pathobiont strains whose circulation in such populations would be favored by global travel.

Despite all the studies that have assessed the pathogenicity of AIEC strains, the genetic factors leading to the AIEC phenotype have not yet been fully characterized. AIEC strains have high genome variability, complicating the identification of specific genetic factors of the pathotype [27]. The FimH adhesin plays an essential role in the virulence of AIEC strains; bacterial adhesion occurs via an interaction between FimH adhesion and mannosylated CEACAM6 adhesion molecules, which are abnormally expressed in the ileal mucosa of 35\% of CD patients in Europe [40]. Through its lectin domain, the FimH protein mediates bacterial adhesion to mannose residues present in the CEACAM6 receptor [41]. The presence of protein polymorphisms resulting from substitutions in the amino acid sequences of some FimH proteins is correlated with an increase in the ability of AIEC to adhere to the intestinal epithelium, increasing the affinity of FimH to mannose residues exposed by the CEACAM6 receptor [24]. The presence of FimH polymorphisms is thought to be one of the virulence evolution mechanisms of AIEC pathogenicity that leads to the development of chronic inflammatory bowel disease in genetically susceptible hosts. In a mouse model, it was reported that mutated FimH variants increased the ability of urinary E. coli isolates to colonize the urinary tract, and these variants were correlated with the overall extraintestinal virulence of $E$. coli $[42,43]$. As noted in this study, significant variations of the FimH protein of the AIEC strains isolated from Brazilian CD patients and controls have not yet been selected, except for the A27V polymorphism. Even if we showed that $\mathrm{A} 27 \mathrm{~V}$ is found in most natural FimH variants, V27A is unlikely to be pathoadaptive for AIEC in CD, as it is not sufficient to mediate a high level of bacteria binding to mannosylated CEACAM6 [24]. Another study argued that the V27A substitution (i.e., with alanine in position 27) is the primary pathoadaptative FimH mutation arising in AIEC isolated from $\mathrm{CD}$ pediatric patients in the entire spectrum of mucosal inflammation [44].

Other AIEC bacterial factors play a role in AIEC virulence. This is the case for the lpfA and gipA genes, which participate in the processes of AIEC interaction and survival in Peyer's patches via $M$ cell interaction $[45,46]$. The type 6 secretion system (T6SS) seems to be strongly involved in AIEC pathogenicity, but the means by which the secretion system contributes to AIEC strain virulence remain to be elucidated. The low prevalence of these genes in the $E$. coli collection isolated in this study suggests that these mucosa-associated $E$. coli strains do not have a highly pathogenic profile. Furthermore, in agreement with the results presented above, the few strains isolated from Brazilian subjects and characterized as AIEC lack the virulence genes of the AIEC strain LF82. Note that in contrast to findings in other reports $[10,24]$, the AIEC strains isolated in this study belong mainly to the B1 phylogroup. These discrepancies suggest that the profile of AIEC differs according to the population in which they are isolated and that environmental, nutritional and genetic factors may be correlated both with susceptibility to disease and the success of colonization of the intestinal mucosa by strains of pathogenic E. coli. In our study, only a few $E$. coli isolates from Brazilian subjects had invasive properties and the ability to replicate within macrophages. In addition, sequence analysis of fim $\mathrm{H}$ genes of $E$. coli strains showed no selection of significant fim $\mathrm{H}$ polymorphisms associated with virulence, unlike in AIEC collections isolated from European patients. This indicates that strains isolated in Brazilian CD patients have probably not yet coevolved to develop a strong adherent-invasive phenotype. We can hypothesize that these B1 and B2 strains selected in Brazilian CD patients will evolve in the future. Thus, it will be of great interest to follow the evolution of the pathogenicity of these strains over the next decade with the aim of gaining a better understanding of the high prevalence of AIEC in developed countries.

\section{Conclusions}

In our study, we have shown that E. coli strains colonize the intestinal mucosa of Brazilian CD patients; however, the strains isolated from Brazilian $\mathrm{CD}$ patients have probably not yet co-evolved with their hosts and therefore have not developed a strong adherent-invasive phenotype. Thus, it will be important to conduct further studies to investigate the evolution of such strains in the Brazilian population to understand the emergence of AIEC pathogens in Western countries or to follow the circulation of the more aggressive AIEC pathobiont strains in Brazilian populations, as these strains could be favored by global travel.

\section{Methods \\ Patients}

Thirty-five subjects, $24 \mathrm{CD}$ patients and 11 controls, were enrolled between March 2012 and August 2013 at the Instituto Alfa de Gastroenterologia (IAG), Hospital das Clínicas (HC), Federal University of Minas Gerais (UFMG), Belo Horizonte, Brazil. The diagnosis of CD in the patients was based on clinical, laboratory, radiological, endoscopic and histopathological findings. The 
control group comprised individuals who had undergone routine ileocolonoscopy at the hospital without any clinicopathological diagnosis of inflammatory disease. None of the patients had received antibiotics in the 2 weeks before sampling. Ileal mucosa biopsy specimens were spread onto MacConkey agar, and the isolates were identified as previously described [47]. The strains were isolated in Brazil and characterized by a metabolic macromethod using an old procedure used in the article published by Pessoa et al. [47]. The characterization of the strains was then confirmed in the laboratory in France, following isolation on Drigalski selective medium. Then, strain identification was confirmed using the well-established API 20 E strips (Biomerieux) method for manual microorganism identification at the species level, and APIWEB software containing all of the API databases was used for a reliable automated interpretation of API strip results.

\section{Bacterial strains}

Of the Enterobacteriaceae isolated from mucosa, 241 were identified as E. coli strains, 183 from the mucosa of $\mathrm{CD}$ patients and 58 from controls. The AIEC reference strain LF82, which was isolated from a chronic ileal lesion of a CD patient [5], and the nonpathogenic E. coli K-12 strain MG1655 were used in the experiments. Bacteria were grown in Luria-Bertani (LB) broth overnight at $37^{\circ} \mathrm{C}$ without shaking.

\section{E. coli phylotyping}

The E. coli phylogroup of each strain was determined by the multiplex PCR technique described by Clermont et al.; this technique assigns strains to phylogroups A, $\mathrm{B} 1, \mathrm{~B} 2$ and D based on the presence/absence of three genes (chuA, yjaA and TspE4.C2) [48].

\section{Cell lines and cell culture}

Human intestinal epithelial Intestine-407 cells (ATCC, CCL-6) were maintained in an atmosphere containing 5\% $\mathrm{CO}_{2}$ at $37^{\circ} \mathrm{C}$ in modified Eagle's Minimal Essential Medium (EMEM, PAA) supplemented with $10 \%$ fetal bovine serum (FBS; Lonza), $1 \%$ nonessential amino acids (PAA), 1\% L-glutamine (PAA), $200 \mathrm{U} / \mathrm{L}$ penicillin, $50 \mathrm{mg} /$ $\mathrm{mL}$ streptomycin and $0.25 \mathrm{mg} / \mathrm{L}$ amphotericin $\mathrm{B}$ with $1 \%$ vitamins (PAA).

Human monocytic THP-1 cells (ATCC, TIB-202) were maintained in an atmosphere containing 5\% $\mathrm{CO}_{2}$ at $37^{\circ} \mathrm{C}$ in RPMI 1640 medium (PAA) supplemented with $10 \% \mathrm{FBS}$ and $1 \% \mathrm{~L}$-glutamine (PAA). THP-1 monocytes were differentiated into macrophages by treatment with $20 \mathrm{ng} / \mathrm{mL}$ phorbol myristate acetate (PMA; Sigma) for $24 \mathrm{~h}$.

\section{Invasion assay}

The number of invasive bacteria in Intestine-407 cells was determined by the gentamicin protection assay as previously described [14]. Briefly, Intestine-407 cells were seeded at a density of $2 \times 10^{5}$ cells $/ \mathrm{cm}^{2}$ in 24 -well plastic plates in the cell culture medium described above without antibiotics. After $24 \mathrm{~h}$ of culture at $37{ }^{\circ} \mathrm{C}$ and $5 \%$ $\mathrm{CO}_{2}$ (allowing cells to reach $80-90 \%$ confluence), the cells were infected at a multiplicity of infection (MOI) of 10 for $3 \mathrm{~h}$. Cells were washed with PBS and incubated in cell culture medium containing $100 \mu \mathrm{g} / \mathrm{mL}$ gentamycin (Euromedex) for $1 \mathrm{~h}$ to kill extracellular bacteria (the bactericidal effect of gentamicin at this concentration was validated on all the strains tested). After washing, the epithelial cells were lysed with $1 \%$ Triton X-100 (Sigma) in deionized water. Samples were diluted and plated onto LB agar plates to determine the number of CFUs 24h later.

\section{Macrophage survival assay}

THP-1 cells were seeded on 24-well tissue culture plates at a density of $2.5 \times 10^{5}$ cells $/ \mathrm{cm}^{2}$ and infected at an MOI of 25 for $20 \mathrm{~min}$. Infected cells were then washed and incubated with culture medium containing $50 \mu \mathrm{g} /$ $\mathrm{mL}$ gentamicin for $40 \mathrm{~min}$ ( $1 \mathrm{~h}$ after infection) or $24 \mathrm{~h}$ (24 h after infection) [49].

\section{Enzyme-linked immunosorbent assay for TNF-a quantification}

Macrophages were infected as described above, and the amount of TNF- $\alpha$ in the culture supernatant was measured. All collected supernatants were frozen at $-80^{\circ} \mathrm{C}$ until processing. Released pro-inflammatory TNF- $\alpha$ cytokines were quantified in the supernatant by ELISA using kits from $R \& D$ systems following the manufacturer's instructions.

\section{Detection of virulence factors by PCR}

The presence or absence of the $h c p 1, h c p 3, \operatorname{lpf} \mathrm{A}$ and gipA genes was analyzed by PCR. The primers, PCR conditions and product sizes are given in Table 6 .

\section{Sequencing of the $\mathrm{fimH}$ gene}

To amplify the fim $\mathrm{H}$ gene, a pair of primers was designed based on conserved regions of the E. coli sequences deposited in GenBank: K-12 MG1655 (NC000913.3), LF82 (AF288194.1), UPEC (NC004431) and APEC 01 (NC008563). Primers and PCR conditions are given in Table 6. After purification with the Wizard SV Gel and PCR Clean-Up System (Promega, Madison, WI, USA), PCR products were sequenced (Sanger sequencing technique using the barcode system, Eurofins Genomics Europe Sequencing, Germany). Nucleotide sequences were obtained from both strands and analyzed 
Table 6 Primer sequences and PCR conditions used to detect the hcp1, hcp3, IpfA, gipA and fimH genes

\begin{tabular}{|c|c|c|c|c|}
\hline Gene & Primer sequencing $\left(5^{\prime}-3^{\prime}\right)$ & PCR conditions & Product (pb) & Reference \\
\hline hcp1 & $\begin{array}{l}\text { F: AAACACCACTGGAGTACCTG } \\
\text { R: TGGTACTTAGCAAGAAAGAGC }\end{array}$ & $95^{\circ} \mathrm{C} 3$ min., 35 cycles $\left(95^{\circ} \mathrm{C} 45\right.$ s., $55^{\circ} \mathrm{C} 30 \mathrm{~s}$, e $72^{\circ} \mathrm{C} 45$ s.) e $68^{\circ} \mathrm{C} 8 \mathrm{~min}$. & 999 & This study \\
\hline hсp3 & $\begin{array}{l}\text { F: CGAAATCAGTCTTGTTCCGC } \\
\text { R: GGGTTCCTTATCGTGTTCT }\end{array}$ & $95^{\circ} \mathrm{C} 3$ min., 35 cycles $\left(95^{\circ} \mathrm{C} 45\right.$ s., $55^{\circ} \mathrm{C} 30$ s, e $72^{\circ} \mathrm{C} 45$ s. $)$ e $68^{\circ} \mathrm{C} 8 \mathrm{~min}$. & 745 & This study \\
\hline IpfA & $\begin{array}{l}\text { F: GGCCTTCTTCAGACGGTA } \\
\text { R: CTGGAAAACTGCGATATCTCC }\end{array}$ & $95^{\circ} \mathrm{C} 3$ min., 35 cycles $\left(95^{\circ} \mathrm{C} 45\right.$ s., $57^{\circ} \mathrm{C} 30$ s, e $72^{\circ} \mathrm{C} 45$ s. $)$ e $68^{\circ} \mathrm{C} 8$ min. & 199 & [45] \\
\hline gipA & $\begin{array}{l}\text { F: GTCGTTGCGCCACCAACAA } \\
\text { R: ACGGCGCAGATGGTAATTCT }\end{array}$ & $94^{\circ} \mathrm{C} 5$ min., 35 cycles $\left(94^{\circ} \mathrm{C} 1 \mathrm{~m} ., 55^{\circ} \mathrm{C} 1 \mathrm{~m}\right.$, e $72^{\circ} \mathrm{C} 30 \mathrm{~s}$.) e $72^{\circ} \mathrm{C} 10 \mathrm{~min}$. & 200 & {$[46]$} \\
\hline$f i m H$ & $\begin{array}{l}\text { F: ATTCCTCACAATCAGCGCAC } \\
\text { R: CGCGTCTTATCTGGCCTACA }\end{array}$ & $95^{\circ} \mathrm{C} 3$ min., 35 cycles $\left(95^{\circ} \mathrm{C} 45\right.$ s., $57^{\circ} \mathrm{C} 30$ s, e $72^{\circ} \mathrm{C} 45$ s. $)$ e $68^{\circ} \mathrm{C} 8 \mathrm{~min}$. & 1125 & This study \\
\hline
\end{tabular}

for editing by the CAP3 Sequence Assembly Program (http://pbil.univ-lyon1.fr/cap3.php) and the BLAST homology search program (blastN) (http://www.ncbi. nlm.nih.gov/BLAST/). Alignment analysis was carried out by the Multalin Page interface program (http://multalin.toulouse.inra.fr/multalin). The sequences were converted into amino acids with the Expasy Translate Tool (http://ca.expasy.org/tools/dna.html).

\section{Statistical analysis}

The data were analyzed with GraphPad Prism software version 5.00 (GraphPad Software, San Diego, California, USA). To compare proportions of strains belonging to different phylogroups, we carried out statistical analysis using the Kruskal-Wallis test adjusted by Dunn's test. To compare the values of bacteria associated with the ileal mucosa or the level of invasion of different isolated bacteria between $C D$ patients and controls, since the values do not present a normal distribution, we used the nonparametric Mann-Whitney test. For each strain, to determine the value corresponding to the number of intramacrophagic bacteria at 24 post-infection was significantly higher than that at $1 \mathrm{~h}$ post-infection, we used the nonparametric Mann-Whitney test. To compare the level of TNF alpha secretion by macrophages infected with AIEC strains at $24 \mathrm{~h}$ post-infection compared to uninfected cells, we used a one-way ANOVA test followed by the Newman-Keuls test. All experiments were performed at least three times. The results with $p<0.05$ were considered significant.

\section{Abbreviations}

CD: Crohn's disease; AIEC: Adherent-invasive Escherichia coli; IBD: Inflammatory bowel disease; ExPEC: Extraintestinal pathogenic E. coli strains; T6SS: Type 6 secretion system; IAG: Instituto Alfa de Gastroenterologia; HC: Hospital das Clínicas; UFMG: Federal University of Minas Gerais; LB: Luria-Bertani; PCR: Polymerase chain reaction; MOI: Multiplicity of infection; SNPs: Single base polymorphisms

\section{Acknowledgements}

The authors would like to thank the staff of the Instituto Alfa de Gastroenterologia (IAG), Hospital das Clínicas (HC), Universidade Federal de Minas Gerais (UFMG) for providing the bowel biopsies. Thanks to the anonymous reviewers and editors for strengthening this manuscript.

\section{Authors' contributions}

RFAC, ADM, FSM and NB contributed to the study design. RFAC collected samples, analyzed and interpreted the patient data and identified E. coli strains under the guidance of MLAF and FSM. RFAC performed E. coli phylotyping, experiments on cell cultures and detection of virulence factors by PCR under the guidance of ADM, MAB and NB. RFAC, FSM and NB analyzed data and also wrote the manuscript. All authors, except for ADM, read and approved the final manuscript. ADM, unfortunately, died during the study execution and, therefore, could not participate in its conclusion. All authors read and approved the manuscript.

\section{Funding}

RFAC received a PhD fellowship from Brazilian Coordenação de Aperfeiçoamento de Pessoal de Nível Superior (CAPES), and the French government's "Eiffel excellence scholarship". This work was financial supported by the Ministère de la Recherche et de la Technologie, Inserm (UMR1071) and INRAE (USC-2018). The funders had no role in the design of the study and collection, analysis, and interpretation of data and in writing the manuscript and decision to publish.

Availability of data and materials

All data generated or analyzed during this study are included in this article.

Ethics approval and consent to participate

All work in this study was approved Ethics Committee of Federal University of Minas Gerais, Brazil (\# CAAE - 00836712.4.0000.5149). Informed consent was obtained from all patients before sample collection.

All participants signed a written consent. No participant was under 16 years old.

Consent for publication

Not applicable.

\section{Competing interests}

None of the investigators has any financial interest or financial conflict with the subject matter or materials discussed in this report. The authors declare they have no competing interests.

\section{Author details}

${ }^{1}$ Departamento de Microbiologia, Instituto de Ciências Biológicas, Universidade Federal de Minas Gerais, Belo Horizonte, Minas Gerais, Brazil. 2Université Clermont Auvergne, Inserm U1071, M2iSH, USC-INRAE 2018, 28 place Henri Dunant, 63000 Clermont-Ferrand, France. ${ }^{3}$ Departamento de Clínica Médica, Faculdade de Medicina, Universidade Federal de Minas Gerais, Belo Horizonte, Brazil. ${ }^{4}$ Instituto Alfa de Gastroenterologia, Hospital das Clínicas, Universidade Federal de Minas Gerais, Belo Horizonte, Minas Gerais, Brazil. ${ }^{5}$ Centre des Sciences du Goût et de l'Alimentation, AgroSup Dijon, CNRS, INRAE, Université Bourgogne Franche-Comté, F-21000 Dijon, France. 
Received: 27 February 2020 Accepted: 12 June 2020

Published online: 23 June 2020

\section{References}

1. Duchmann R, Zeitz M. Crohn's disease. In: Ogra PL, Mestecky J, Lamm ME, Strober W, Bienenstock J, McGhee JR, editors. Mucosal Immunology. San Diego: Academic; 1999. p. 1055-80.

2. Ogura Y, Bonen DK, Inohara N, Nicolae DL, Chen FF, Ramos R, et al. A frameshift mutation in NOD2 associated with susceptibility to Crohn's disease. Nature. 2001;41:603-6.

3. Rutgeerts P, Goboes K, Peeters M, Hiele M, Penninckx F, Aerts R, et al. Effect of faecal stream diversion on recurrence of Crohn's disease in the neoterminal ileum. Lancet. 1991;338:771-4.

4. Nataro JP, Kaper JB. Diarrheagenic Escherichia coli. Clin Microbiol Rev. 1998; 11:142-201.

5. Darfeuille-Michaud A, Neut C, Barnich N, Lederman E, Di Martino P, Desreumaux P, Gambiez L, et al. Presence of adherent Escherichia coli strains in ileal mucosa of patients with Crohn's disease. Gastroenterology. 1998;115: 1405-11.

6. Neut C, Bulois P, Desreumaux P, Membre JM, Lederman E, Gambiez L, et al. Changes in the bacterial flora of the neoterminal ileum after ileocolonic resection for Crohn's disease. Am J Gastroenterol. 2002;97:939-46.

7. Martin HM, Campbell BJ, Hart CA, Mpofu C, Nayar M, Singh R, et al. Enhanced Escherichia coli adherence and invasion in Crohn's disease and colon cancer. Gastroenterology. 2004;127:80-93.

8. Conte MP, Schippa S, Zamboni I, Penta M, Chiarini F, Seganti L, et al. Gutassociated bacterial microbiota in paediatric patients with inflammatory bowel disease. Gut. 2006;55:1760-7.

9. Baumgart M, Dogan B, Rishniw M, Weitzman G, Bosworth B, Yantiss R, et al. Culture independent analysis of ileal mucosa reveals a selective increase in invasive Escherichia coli of novel phylogeny relative to depletion of Clostridiales in Crohn's disease involving the ileum. ISME J. 2007;1:403-18.

10. Kotlowski R, Bernstein CN, Sepehri S, Krause DO. High prevalence of Escherichia coli belonging to the B2+D phylogenetic group in inflammatory bowel disease. Gut. 2007:56:669-75.

11. Sasaki M, Sitaraman SV, Babbin BA, Gerner-Smidt P, Ribot EM, Garrett N, et al. Invasive Escherichia coli are a feature of Crohn's disease. Lab Investig. 2007;87:1042-54.

12. Eaves-Pyles T, Allen CA, Taormina J, Swidsinski A, Tutt CB, Jezek GE, et al. Escherichia coli isolated from a Crohn's disease patient adheres, invades, and induces inflammatory responses in polarized intestinal epithelial cells. Int J Med Microbiol. 2008;298:397-409.

13. Martinez-Medina M, Aldeguer X, Lopez-Siles M, González-Huix F, López-Oliu C, Dahbi G, et al. Molecular diversity of Escherichia coli in the human gut: new ecological evidence supporting the role of adherent-invasive $E$. coli (AIEC) in Crohn's disease. Inflamm Bowel Dis. 2009;15:872-82.

14. Boudeau J, Glasser AL, Masseret E, Joly B, Darfeuille-Michaud A. Invasive ability of an Escherichia coli strain isolated from the ileal mucosa of a patient with Crohn's disease. Infect Immun. 1999;67:4499-509.

15. Glasser AL, Boudeau J, Barnich N, et al. Adherent invasive Escherichia coli strains from patients with Crohn's disease survive and replicate within macrophages without inducing host cell death. Infect Immun. 2001;69:5529-37.

16. Kaper JB, Nataro JP, Mobley HL. Pathogenic Escherichia coli. Nat Rev Microbiol. 2004;2:123-40.

17. Clarke DJ, Chaudhuri RR, Martin HM, Campbell BJ, Rhodes JM, Constantinidou C, et al. Complete genome sequence of the Crohn's disease-associated adherent-invasive Escherichia coli strain HM605. J Bacteriol. 2011;193:4540.

18. Krause DO, Little AC, Dowd SE, Bernstein CN. Complete genome sequence of adherent invasive Escherichia coli UM146 isolated from lleal Crohn's disease biopsy tissue. J Bacteriol. 2010;193:583.

19. Miquel S, Peyretaillade E, Claret L, de Vallee A, Dossat C, Vacherie B, et al. Complete genome sequence of Crohn's disease-associated adherentinvasive E. coli strain LF82. PLoS One. 2010:5:e12714.

20. Nash JH, Villegas A, Kropinski AM, Aguilar-Valenzuela R, Konczy P, Mascarenhas M, et al. Genome sequence of adherent-invasive Escherichia coli and comparative genomic analysis with other E. coli pathotypes. BMC Genomics. 2010;11:667.

21. Vejborg RM, Hancock V, Petersen AM, Krogfelt KA, Klemm P. Comparative genomics of Escherichia coli isolated from patients with inflammatory bowel disease. BMC Genomics. 2011;12:316.
22. Santos AC, Romeiro F, Sassaki L, Rodrigues J. Escherichia coli from Crohn's disease patient displays virulence features of enteroinvasive (EIEC), enterohemorragic (EHEC), and enteroaggregative (EAEC) pathotypes. Gut Pathog. 2015;7:2.

23. Darfeuille-Michaud A, Boudeau J, Bulois P, Neut C, Glasser AL, Barnich N, et al. High prevalence of adherent-invasive Escherichia coli associated with ileal mucosa in Crohn's disease. Gastroenterology. 2004;127:412-21.

24. Dreux N, Denizot J, Martinez-Medina M, Mellmann A, Billig M, Kisiela D, et al. Point mutations in FimH adhesion of Crohn's disease associated adherentinvasive Escherichia coli enhance intestinal inflammatory response. PLoS Pathog. 2013;9:e1003141.

25. Sartor RB. Microbial influences in inflammatory bowel diseases. Gastroenterology. 2008;134:577-94.

26. Carrière J, Darfeuille-Michaud A, Nguyen HT. Infectious etiopathogenesis of Crohn's disease. World J Gastroenterol. 2014;20:12102-17.

27. Martinez-Medina M, Garcia-Gil LJ. Escherichia coli in chronic inflammatory bowel diseases: an update on adherent invasive Escherichia coli pathogenicity.World J Gastrointest Pathophysiol. 2014;5:213-27.

28. Swidsinski A, Ladhoff A, Pernthaler A, Swidsinski S, Loening-Baucke V, Ortner $M$, et al. Mucosal flora in inflammatory bowel disease. Gastroenterology. 2002;122:44-54.

29. Selander RK, Caugant DA, Whittam TS. Genetic structure and variation in natural populations of Escherichia coli. In: Neidhardt FC, Ingraham JL, Low KB, Magasanik B, Schaechter M, Umbarger HE, editors. Escherichia coli and Salmonella typhimurium: cellular and molecular biology. Washington, D.C.: American Society for Microbiology; 1987. p. 1625-48.

30. Herzer PJ, Inouye S, Inouye M, Whittam TS. Phylogenetic distribution of branched RNA-linked multicopy single-stranded DNA among natural isolates of Escherichia coli. J Bacteriol. 1990;172:6175-81.

31. Wirth T, Falush D, Lan R, Colles F, Mensa P, et al. Sex and virulence in Escherichia coli: an evolutionary perspective. Mol Microbiol. 2006;60:1136-51.

32. Moulin-Schouleur M, Reperant M, Laurent S, Bree A, Mignon-Grasteau S, et al. Extraintestinal pathogenic Escherichia coli strains of avian and human origin: link between phylogenetic relationships and common virulence patterns. J Clin Microbiol. 2007:45:3366-76.

33. Ryan P, Bennett MW, Aarons S, Lee G, Collins JK, O'Sullivan GC, O'Connell J, Shanahan F. PCR detection of Mycobacterium paratuberculosis in Crohn's disease granulomas isolated by laser capture microdissection. Gut. 2002;51:665-70.

34. Nowrouzian FL, Adlerberth I, Wold AE. Enhanced persistence in the colonic microbiota of Escherichia coli strains belonging to phylogenetic group B2: role of virulence factors and adherence to colonic cells. Microbes Infect. 2006;8:834-40.

35. Sepehri S, Kotlowski R, Bernstein CN, Krause DO. Phylogenetic analysis of inflammatory bowel disease associated Escherichia coli and the fimH virulence determinant. Inflamm Bowel Dis. 2009:15:1737-45.

36. Schippa S, Conte MP, Borrelli O, lebba V, Aleandri M, Seganti L, et al. Dominant genotypes in mucosa-associated Escherichia coli strains from pediatric patients with inflammatory bowel disease. Inflamm Bowel Dis. 2009;15:661-72.

37. Sepehri S, Khafipour E, Bernstein CN, Coombes BK, Pilar AV, Karmali M, et al. Characterization of Escherichia coli isolated from gut biopsies of newly diagnosed patients with inflammatory bowel disease. Inflamm Bowel Dis. 2011;17:1451-63.

38. Elliott TR, Hudspith BN, Wu G, Cooley M, Parkes G, Quiñones B, et al. Quantification and characterization of mucosa-associated and intracellular Escherichia colli in inflammatory bowel disease. Inflamm Bowel Dis. 2013;19:2326-38.

39. Palmela C, Chevarin C, Xu Z, Torres J, Sevrin G, Hirten R, Barnich N, et al. Adherent-invasive Escherichia coli in inflammatory bowel disease. Gut. 2018; 67:574-87.

40. Barnich N, Carvalho FA, Glasser AL, Darcha C, Jantscheff P, Allez M, et al. CEACAM6 acts as a receptor for adherent-invasive E. coli, supporting ileal mucosa colonization in Crohn disease. J Clin Invest. 2007;117:1566-74.

41. Nilsson LM, Thomas WE, Sokurenko EV, Vogel V. Elevated shear stress protects Escherichia coli cells adhering to surfaces via catch bonds from detachment by soluble inhibitors. Appl Environ Microbiol. 2006;72:3005-10.

42. Hommais F, Gouriou S, Amorin C, Bui H, Rahimy MC, Picard B, et al. The FimH A27V mutation is pathoadaptive for urovirulence in Escherichia coli B2 phylogenetic group isolates. Infect Immun. 2003;71:3619-22.

43. Sokurenko EV, Chesnokova V, Doyle RJ, Hasty DL. Diversity of the Escherichia coli type 1 fimbrial lectin. Differential binding to mannosides and uroepithelial cells. J Biol Chem. 1997;272:17880-6. 
44. lebba V, Conte MP, Lepanto MS, Di Nardo G, Santangelo F, et al. Microevolution in fimH gene of mucosa-associated Escherichia coli strains isolated from inflammatory bowel disease pediatric patients. Infect Immun. 2012:80:1408-17.

45. Chassaing B, Rolhion N, de Vallée A, Salim SY, Prorok-Hamon M, Neut C, et al. Crohn disease-associated adherent-invasive E. coli bacteria target mouse and human Peyer's patches via long polar fimbriae. J Clin Invest. 2011;121:966-75.

46. Vazeille E, Chassaing B, Buisson A, Dubois A, de Vallée A, Billard E, et al. GipA factor supports colonization of Peyer's by Crohn's disease-associated Escherichia coli. Inflamm Bowel Dis. 2016;22:68-81.

47. Pessoa GVA, Silva EAM. Meios de Rugai e lisina-motilidade combinados em um só tubo para a identificação presuntiva de enterobactérias. Rev Inst Adolfo Lutz. 1972;32:97-100.

48. Clermont O, Bonacorsi S, Bingen E. Rapid and simple determination of the Escherichia coli phylogenetic group. Appl Environ Microbiol. 2000;66:4555-8.

49. Bringer MA, Barnich N, Glasser AL, Bardot O, Darfeuille-Michaud A. HtrA stress protein is involved in intramacrophagic replication of adherent and invasive Escherichia coli strain LF82 isolated from a patient with Crohn's disease. Infect Immun. 2005;73:712-21.

\section{Publisher's Note}

Springer Nature remains neutral with regard to jurisdictional claims in published maps and institutional affiliations.

- fast, convenient online submission

- thorough peer review by experienced researchers in your field

- rapid publication on acceptance

- support for research data, including large and complex data types

- gold Open Access which fosters wider collaboration and increased citations

- maximum visibility for your research: over $100 \mathrm{M}$ website views per year

At $\mathrm{BMC}$, research is always in progress.

Learn more biomedcentral.com/submissions 